\title{
BEAM DEVELOPMENTS FOR THE HARWELL. MICROPROBE SYSTEM
}

\author{
P.M. READ. J.A. COOKSON and G.D. ALTON *

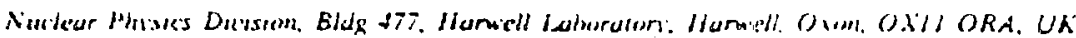

\begin{abstract}
A consequence of the rapid development of micron and submicron size electronic devices is the diminished zpplicability of high energy in microprnhes with their prexent resolution limitations to the study of such enmponcnts. Although submicron beams have heen reported the availabic beam current is barely sufliciently for PIXE and is not adcquatc for RBS. This lack of lateral resolution is duc in low bcam brightness at the microprobe object and abcriations in the focussing clements. As part of a program to address these problems the Harweli microprobe lens has heen relocated on a neu 5 MV Ladderton accelerator. The increased brightness and improved stability of this facility has $\infty$ far icd to a reduction in heam size from $3 \times 3 \mu \mathrm{m}^{2}$ to about $2 \times 2 \mu \mathrm{m}^{2}$.

The feasibility of using a liquid metal ion source has been examined with a vicw to achieving more substantial increases in brightness. While such sources have brightness approximately $10^{5}$ times greater than conventional gascous sources the highly divergent nature of the beam presents problems for the bcam iranspont sysiem. The use of a liquif melal source on the cceelerator has bern successfully demonstrated but it indicates the need for a special low aberration injection leas if brightness is te be maintained.
\end{abstract}

\section{Introduction}

Since the development of the Harwell microprobe [1] in 1970 the facility has been exiensively used for studies in nuclear science, metallurgy, biology. geology and microelectronics. During this preriod a beam with dimensions $3 \times 3 \mu \mathrm{m}^{2}$ and current of $300 \mathrm{pA}$ has been available for proton induced $X$-ray emission (PIXE) scans. The lower cross-section techniques of Rutherford backscastering spectrometry (RBS) and nuciear ieaction analysis (NRA) have typically used rather larger spot sizes with currents of a lew nA. In order to increase the capabilities of the microprobe, particularly in rclation to the development of micron and submicron size electronic devices, smaller and brighter beam spots are desirabie. Attempts to improve lateral resolution, by eisher decreasing the object slit size or the angular acceptance of the focussing lens, result in a reduction in beam current to a level such that scan times are impractical. This problem is due to a lack of beam brightness at the microprobe object, which is altributable to the intrinsic properties of the ion source, aberrations in the accelerator's various optical elements and the voltage fluctuations of the accelerator. Given sufficient brightness the object slits can be closed down to reducc the lirst order image size and a modest reduction in the angular acceptance of the microprobe lens can ensure that spherical aberrations, which depend upon the cube of angle. do not dominate. As chromatic aberrations depend only linearily on angular acceptance they would

- On tcmporañ attactument froun. Phy'sics Division. Oak Ridgc National Labnratory. Oatk Ridge. Tennenver. USA. then be likely to dominate the spot size ualess the beam cnergy spread could be reduced below present values.

A route which could lead to significant improvements in resolution in such facilities is through the use of high brightness sources such as the proton field ionization ( $F I$ ) source [2] or the liquid metal ion source [3] (LMIS). These sources have reported brightnesses $[4,5]$ of up to $10^{5}$ times greater than the $r$ ion source currently in use on this facility. However, it is not clear that advantage can be taken of this improved brightness on a high energy microprobe. In the first instance a source must operate in the hostile environment of a high voltage terminal and provide a reliable beam with a reasonable lifetime. Secondly, the accelerator must be able to transmit the high brightness beam to the microprobe system without dramatic degradation through aberrations.

The FI source originally suffered from lifetimes of only about $10 \mathrm{~h}$ due to deformation of the field emitter tip by backstreaming negative ions. More recenly the use of iridium emitters has increased this lifetime to in excess of $60 \mathrm{~h}$. However, the source output is limited to about $20 \mathrm{nA}$ [S] and attempts to increase it have led to desiructive discharges from the emitter tip. This current would be usrable in a microprobe provided it were not greatly reduced by angular acceptance defining apertures in the accelerator and that the accelerator could adequately stabilise on the small current. In contrast the LMIS has lifetimes in excess of $1000 \mathrm{~h}$ and has the capability to produce tens of $\mu \mathrm{A}$ of beam current. As the source matcrial is metal it does not produce a gas load so that pumping in the high voltage terminal is not necessary. A disadvantage of the source is that the beam 
is highly divergent and will require carcful nianipulation. Furthermore LMISs are most widely proven fr." heavy metals such as gallium. jridium and gold which are of little value for PIXE, RBS or NRA. A lithium source, which would fill our RBS requirentents, part of the PIXE requirement and permit NRA of bydrogen using the ${ }^{1} \mathrm{H}\left({ }^{\circ} \mathrm{Li} \text {. }{ }^{3} \mathrm{He}\right)^{4} \mathrm{Hc}$. ${ }^{1} \mathrm{H}\left({ }^{7} \mathrm{Li} \text {. }{ }^{4} \mathrm{He}\right)^{3} \mathrm{Hc}$ or ${ }^{1} \mathrm{H}\left({ }^{7} \mathrm{Li}, \mathrm{Y}\right)^{x} \mathrm{Be}$ reaction, has been reported [6] but because of the metal's chemical activity requires develop. ment.

In the presert paper we describe progress on a three stage programme of microprobe development at Harwell. The first stage consisted of the relocation of the Hanuell microprobe lens from an old $3 \mathrm{MV}$ Van de Graaff to a recently commissioned $5 \mathrm{MV}$ Laddertron accelerator [7]. This move allowed us to take advantage 0 : the improved brightness and high stability of the Laddertron. Stage two is a tuning exercise with an objective of achieving the present state of the ant $1 \mu \mathrm{m}$ spot with a current of $100 \mathrm{pA}[8.9]$, which is mainly used for PIXE analysis of biological specimens. The last stage aims towards submicron beams for RBS and NRA and is presently concentrating on the possible potencial of a LMiS.

\section{The Laddertron microprobe facility}

\subsection{Acceleraior}

The Laodertron is a vertical accelerator with the high voltage termisa' supported on four insulating legs constructed from borosilicate glass and stainless steel electrodes. Voltage grading down the column and accelerator tube is provioed by metal oxide resistors which zif 228 from one equipotential plane to another. The total column resistance of $4.5 \times 10^{10}$ jeads to a high voltage terminal time constant CR of $7 \mathrm{~s}$. Charging is provided by a Laddertron which is constructed from siainjess steel rungs and insulating PETP beads. The maximum charging cuired used to date is $240 \mu \mathrm{A}$ at a terminaj voltage of $5 \mathrm{MV}$. Power for terminal supplies and controls is provided by an alternator driven by a rotary shaft. The accelerator is stabilised with a convenlional feed back loop comprised of a corona probe and either a generaling voltmeter or pickoll slits.

A schematic of beam transport in the microprobe facility is shown in lig. 1. lons are generated in an of source and typically extrarted from a $1.5 \mathrm{~mm}$ ठ canal at $2 \mathrm{keV}$. The beam is accelerated to about $20 \mathrm{keV}$ prior to focussing at the gap lens whose function is to match the injection energy to the tube voltage gradient and hence keep the focal length of ine tube constant for different tesminal voltages. After emerging from the areelerator tube the beam passes round a $90^{\circ}$ analysing magnet and is focussed into the stabiliser slits. First order ion optics of the accelerator calculated using
OITRYK $[10]$ are shown in fig. 2.

Inmediatcly downstrcam of the stabilizer slits are a set of steering coils and then the microprobe object slits. A further set of sitis defines the angular acceptance of the microprobe iens. This lens, seen in lig 3. consists of four magnetic quadrupoles of geometric length 180.5 $\mathrm{mm}$. poic gap $38.4 \mathrm{~mm}$ and separation $45 \mathrm{~mm}$. The quadrupoles may be excited separately or in coupied mondes. The image distance is $210 \mathrm{~mm}$ and the object distance. depending upon the number of quadrupoles used, varies from 5785 10 $6235 \mathrm{~mm}$.

An estimate of the proton beam brightness at $3 \mathrm{McV}$ was made using the microprobe object and angular acceptance limiting slits. The object slies defjied a 0.5 $\mathrm{mm}$ square source and the acceptance slits a divergence half angle of $0.23 \mathrm{mrad}$. The transmitted beam of 500 $\mathrm{nA}$ has a brightness, given by $B=I /\left(\pi^{2} E^{2} V\right)$. where $I$ is current, $E$ is the two dimensional emittance and $V$ is beam cnergy, of $3 \mu \mathrm{A} /\left(\mathrm{mm}^{2} \mathrm{mrad}^{2} \mathrm{MeV}\right)$. Bearn current intensity on target has a low frequency peak to pcak variation at the $10 \%$ level and a $400 \mathrm{~Hz}$ ripple of about 5\%. The latter is due to the effect of alternator ripple on the jon source extract power supply. The current stability is dramatially better than the old 3 MV accelerator and is quite satisfactory for microprobe applications. The improved de stability is probably the single most important factor in the threefold improvement in brightness from the value of $1 \mu \mathrm{A} /$ $\mathrm{mm}^{2} \mathrm{mrad}^{2} \mathrm{McV}$ obtained with the $3 \mathrm{MV}$ accelerator.

Beam energy spread has been measured using the well-known ${ }^{27} \mathrm{Al}\left(\mathrm{p}_{\dot{*}} \gamma\right)^{2 \mathrm{Sk}} \mathrm{Si}$ resonance at $991.9 \mathrm{keV}$. The target was a $800 . \dot{A}$ thick freshly evaporated aluminium nilm on tantajum baciking Beam energy was scanned through the resonance by fixing the accelerator energy slightly above the resonance and applying a variable positive bias to the target. Gamma rays were detected in a sodium iodide detector, amplified and passed through a discriminator with a lower level sit at $1.4 \mathrm{MeV}$. A computer controlled CAMAC system determiaed the shape of the excitation function averaged over several voltage cycles. Shortly after commissioning the Laddertron the energy spread was measured to be $590 \mathrm{eV}$ fwhm. More recently the prower supply defining the energy of the beam injected into the accelerator has been replaced by a high stability supply. The corona needles which had a tip sadius of $150 \mu \mathrm{m}$ have been replaced with needles of tip radius $30 \mu \mathrm{m}$. It is known that the blunter needles tend to spark. because of the higher electric ficld required to deliver the same emission curent and this can give unstable operation [11]. Since these changes the beam energy spread has been measured to be $40 \mathrm{eV}$ fwhm (see Jig. 4). This represents a $40 \%$ reduction in energy spread compared to the 3 MV accelerator. In microprobe operation the beam would be more tightly collimated and its energy spread should be lower than the above value. 


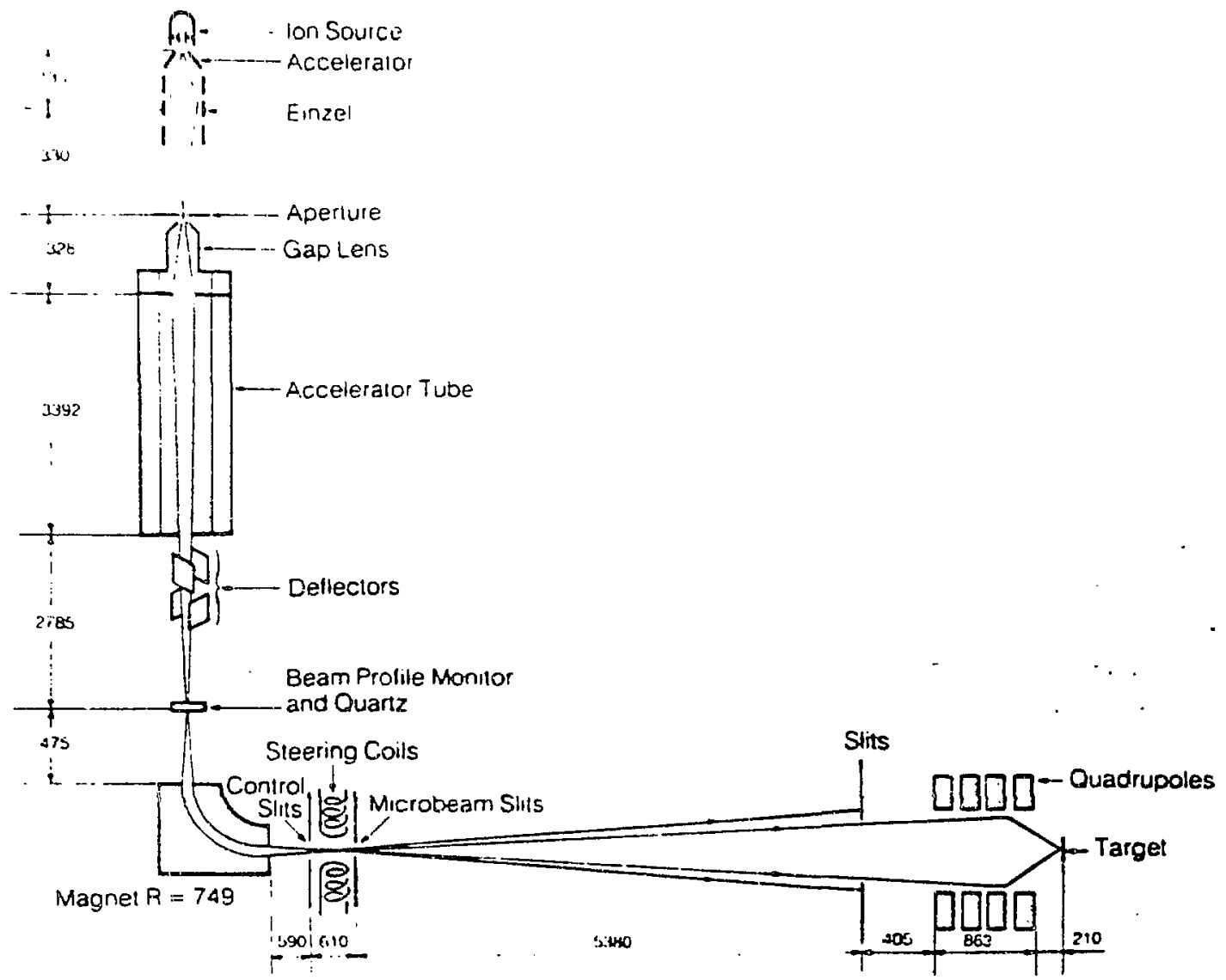

Fig. 1. A schematic diagram of the Laddertron accelerator and microprobe facility.

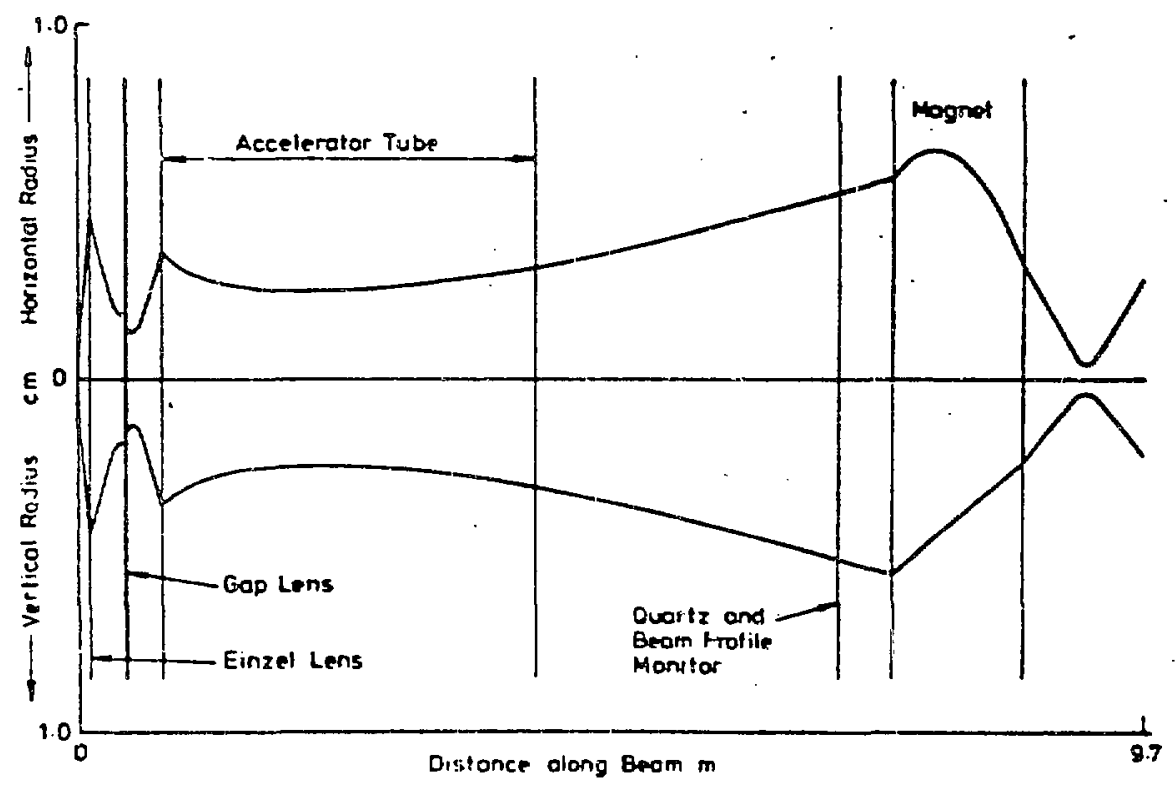

Fig 2 . The first ordet ion optics of the ncoeierator at a terminal voltage of 4 MV. The ion souree is of the $r$ type. providing a beam at $20 \mathrm{keV}$ with a viriual source radius of $0.75 \mathrm{~mm}$ and half angle of $33 \mathrm{mrad}$. 


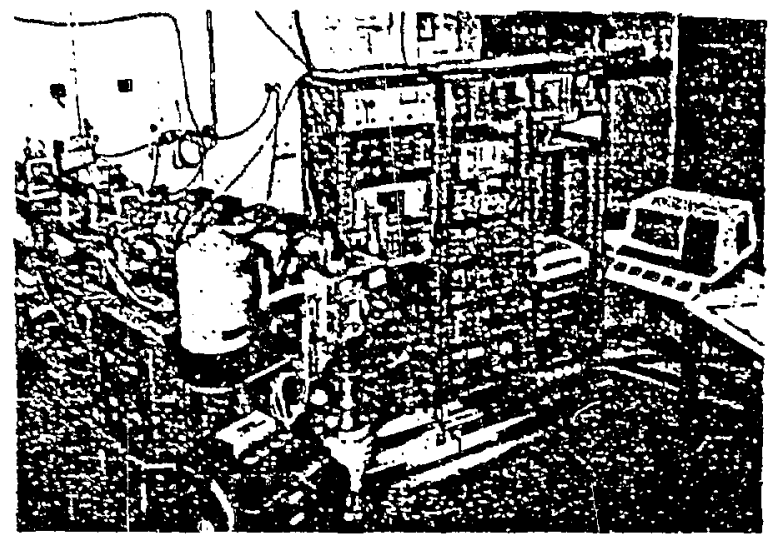

Fig. 3. A pholograph of the microprobe lacility showing the four quadrupole lens, scattering chamber and conirnl and data acquisition clectronics. The arigular acceplance limiting slits can be seen slighily upstream of the lens.

\subsection{Microprobe image}

The first, second and third order imaging properties of the microprobe lens have been calculated using the data of Grime and Watt [12]. They calculate aberration coefficients by numerically solving the equations of motion for a representative set of particles in the beam passing through the quadrupoic field and tabulate the results for a variety of lens configurations. The configurations we have considered are: the Russian quadruplet used in the original Harwell microprobe [1] where
Table 1

Parameters of the microprote arranged in quadruplet. Iriplet and Jouhici modes. A quadrupoic is described as converging (C) if an ion moving in the horizontal plane is deflected imwards the axis and diverging (D) if the particle is dellected usay from the axis. Spatial and angular dimensions for the aberrations are in $\mu \mathrm{m}$ and mrad respectively.

\begin{tabular}{|c|c|c|c|}
\hline & $\begin{array}{l}\text { Quadruplet } \\
\text { П7 } \\
\text { CDCD } \\
\end{array}$ & $\begin{array}{l}\text { Triplet } \\
\text { CDC }\end{array}$ & $\begin{array}{l}\text { Doublet } \\
C D\end{array}$ \\
\hline Image distance & $210 \mathrm{~mm}$ & $210 \mathrm{~mm}$ & $210 \mathrm{~mm}$ \\
\hline \multicolumn{4}{|l|}{ Object } \\
\hline dislance & $5785 \operatorname{man}$ & $601 \mathrm{cmm}$ & $6235 \mathrm{~mm}$ \\
\hline \multicolumn{4}{|l|}{ Verical } \\
\hline $\begin{array}{l}\text { demagnification } \\
\text { Horizontal }\end{array}$ & -9.76 & -19.7 & -43.3 \\
\hline demagnification & -9.76 & 70.0 & -6.18 \\
\hline \multicolumn{4}{|c|}{ Chromalic aberration coefficients } \\
\hline$\langle x \mid \theta 8\rangle$ & 10.28 & -35.16 & 15.17 \\
\hline$\langle y \mid \phi \delta\rangle$ & 16.07 & 101.3 & 13.16 \\
\hline \multicolumn{4}{|c|}{ Spherical aberration coefficients $\times 10^{-3}$} \\
\hline$\left\langle x \mid \theta^{3}\right\rangle$ & -6.97 & 193 & - $\quad-5.97$ \\
\hline$\left\langle y \mid \phi^{3}\right\rangle$ & -24.6 & -1343 & -30.0 \\
\hline$\left\langle\pi \mid \theta \phi^{2}\right\rangle$ & -35.2 & 348 & -64.3 \\
\hline$\left\langle y\left(\phi \theta^{2}\right)\right.$ & -33.0 & -1290 & -9.29 \\
\hline
\end{tabular}

the first and last quadrupoles, and the inver two quadrupoles are excited equally; the Oxford coupled triplet [8] which has the first two quadrupoles equaliy excited: and the simple doublet. Demagnifications and aberration coefricients are presented in table 1. The

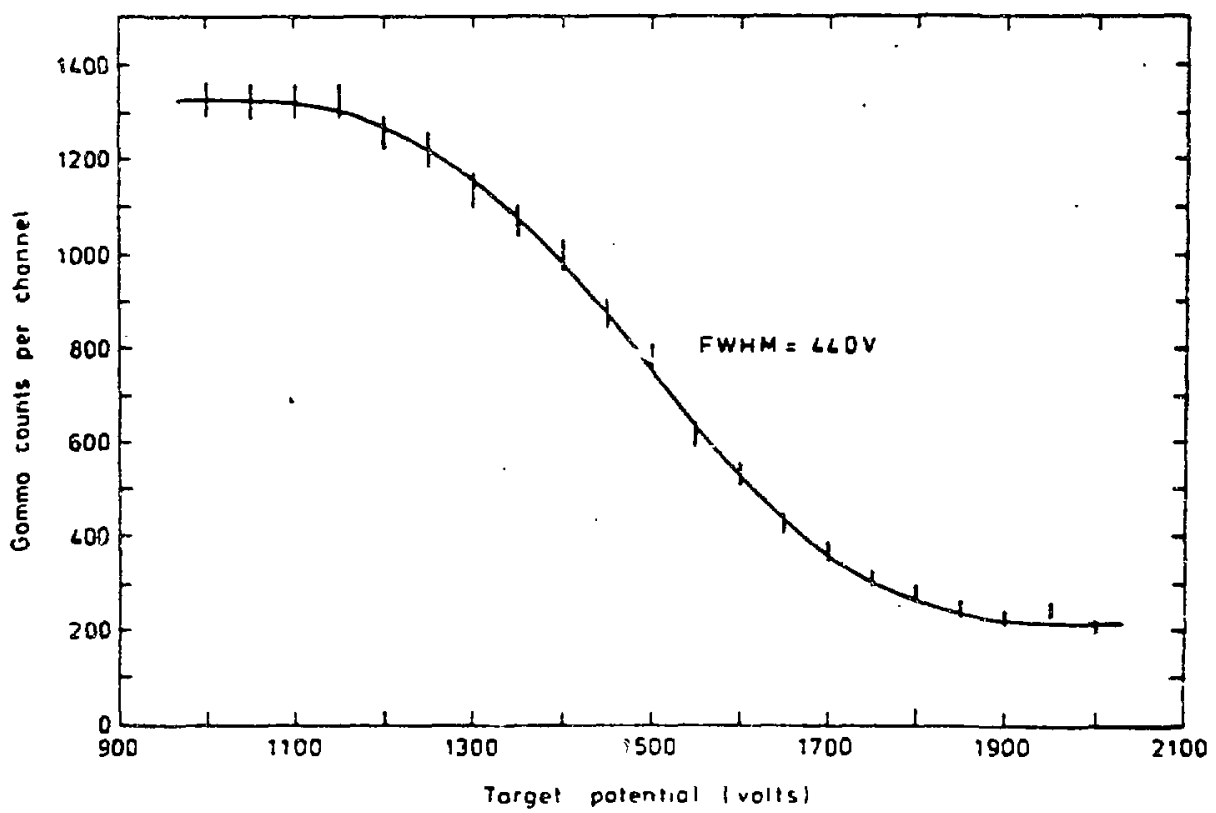

Fig. 4. The cenergy spread of a proirnn heam from the accelerator was measured by scanning the bearri energy nver the ${ }^{27} \mathrm{Akp}$. $\left.\mathrm{Y}\right)^{2 x} \mathrm{Si}$ resonance $21991.9 \mathrm{kcV}$. The fwhm energy spread is $440=\mathrm{V}$. 
Table :

Coniribulions to a $1 \mathrm{\mu m}^{2}$ spot duc 10 first noder imaging and chromalic and spherical aberrations. The fractional momentum spread is taken in be $\pm 1.2 \times 10^{-4}$.

\begin{tabular}{|c|c|c|c|}
\hline & Quadruplet & Triplet & Doublet \\
\hline $\begin{array}{l}\text { Vartical object } \\
\text { aperiure } y(\mu \mathrm{m})\end{array}$ & 6.25 & 12.6 & 27.7 \\
\hline \multicolumn{4}{|l|}{ Horizontal object } \\
\hline$\therefore$ veriure $x(\mu \mathrm{m})$ & 6.25 & 44.8 & 3.95 \\
\hline \multicolumn{4}{|l|}{ Vertical divergence } \\
\hline \multicolumn{4}{|l|}{ Horizontal divergence } \\
\hline \multicolumn{4}{|l|}{ First order image } \\
\hline$\Delta x(\mu \mathrm{m})$ & 0.64 & 0.64 & 0.64 \\
\hline$\Delta y(\mu \mathrm{m})$ & 0.64 & 0.64 & 0.64 \\
\hline \multicolumn{4}{|l|}{ Chromatic aberrations } \\
\hline $2 \Delta x_{\mathrm{ch}}(\mu \mathrm{m})$ & 0.59 & 0.67 & 0.55 \\
\hline $2 \Delta y_{\mathrm{th}}(\mu \mathrm{m})$ & 0.54 & 0.68 & 0.57 \\
\hline \multicolumn{4}{|l|}{ Spherical aberrations } \\
\hline $2 \Delta x_{\text {sph }}(\mu \mathrm{m})$ & 0.52 & 0.24 & 0.67 \\
\hline $2 \Delta V_{\text {rph }}(\mu m)$ & 0.67 & 0.52 & 0.43 \\
\hline Acoeplance $\left(\mu \mathrm{m}^{2} \mathrm{mrad}^{2}\right)$ & 5.3 & 5.1 & 11.8 \\
\hline
\end{tabular}

quadrupiet has a low demagnification and small beam optical aberrations. The image size will therefore be - strongly dependent upon the dimensions and quality of the object slits. For the triplet. demagnification is high and buam optical abcrration coefficients are corre. spondingly high Paracatic aberrations arising Irom misalignments, rotations and harmonic contamination of the quadrupoic field will also have large coeflicients. The characteristics of the doublet configuration are iniermediate between the quadruplet and triplet. Contributions to a $1 \mathrm{\mu m}^{2}$ image for the three quadrupole configurations described above are presented in table 2. The first order image size was lixed at $0.64 \mu \mathrm{m}$ and the angular acceptance of the lens adjusted to give similar contributions from chromatic and spherical aberrations. Taking the acceptance of each system as a figure of merit we find the value for the doublet to be about double that for either the quadruplet or triplet.

To determine the size of the microprobe beam it was first optimized on a quarz viewed by a $\times 100$ microscope. The beam was then scanned across a $12 \mu \mathrm{m}$ wide strip of platinum on silicon substrate and the intensity of Pf L X-rays observed as a function of scan voliage. In tests so far the doublet gave the best result with a beam spot of $2.2 \times 2.2 \mu \mathrm{m}^{2}$ and current of $150 \mathrm{pA}$. Another scan across a $8 \mu \mathrm{m}$ wide aluminium strip on silicon substrate indicated a resolution in one direction of $1.4 \mu \mathrm{m}$ (see lig. 5) but the specimen was unsuitable for measurement in the other direction. A more suitable test specimen is being prepared.

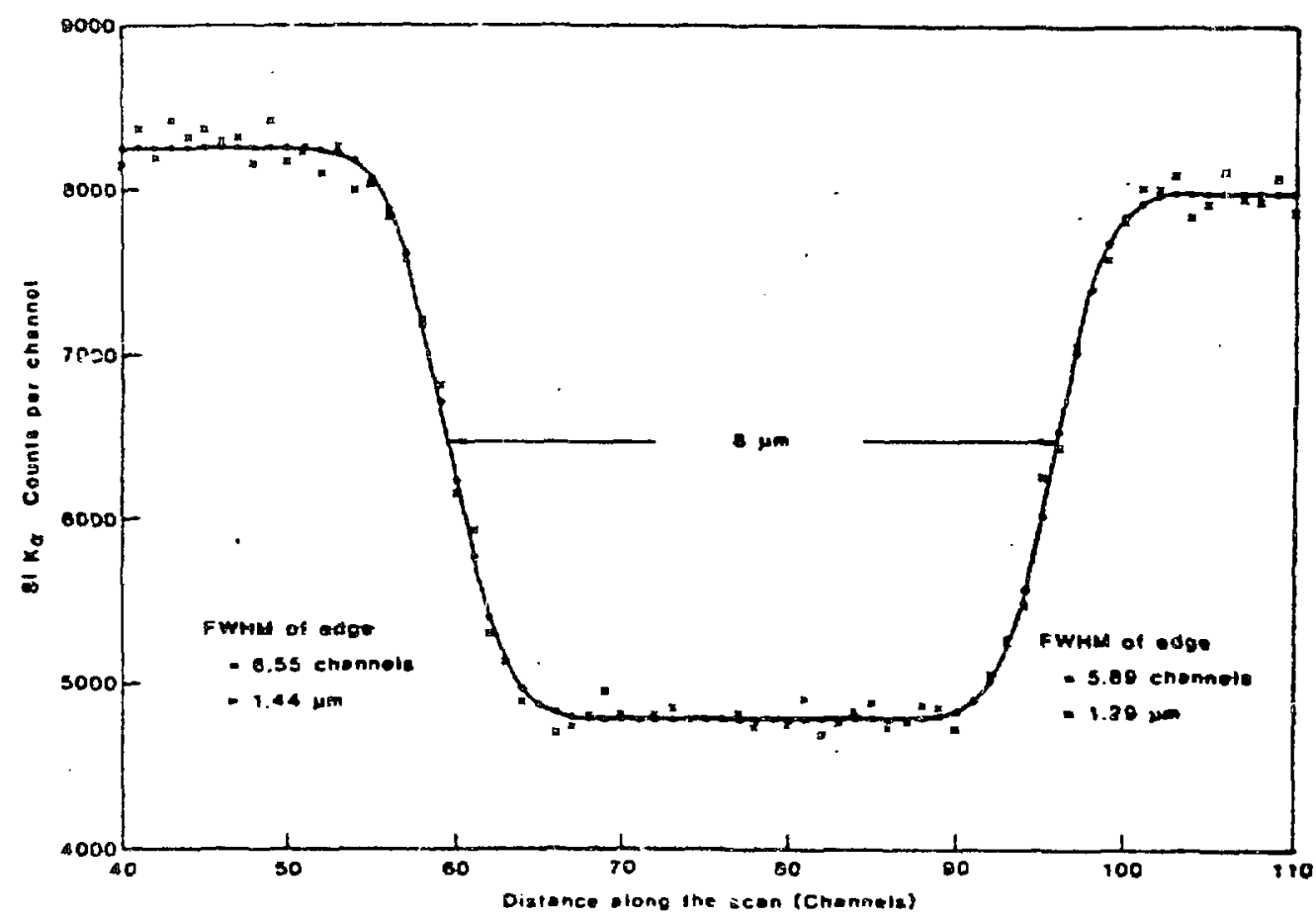

Fig 5. The silicon $K$. X-ray yicld as a function of scan position across a $8 \mu \mathrm{m}$ wide aluminium strip on silicon substralc: the crosses represcrit data and the circles fit points. 


\section{Besm development}

\section{J. Ion source}

This section describes feasibiluty studies for the usc of a IMIS on a high energy accelerator and for ultimatcly using the bcam for microprobe applications. The majority of work has been performed using a gallium source [13] because of its availability from the manulacturers of low energy ion probes. The LMIS consists of a tungsten needle with a tip radius of about $10 \mu \mathrm{m}$ welted with gallium and supported in a reservoir tube. It is installed in a source body containing a reservoir heater and extraction clectrode (fig. 6). The heater has been incorporated for subsequent work with lithium but was not used with the gallium source. Ions are extracted rrom the needle tip by applying between 5 and o $\mathrm{kV}$ to the extractor. The ion current is controlled by the extractuon voltage and the source is stable over long periods with currents at asy set leve! between a few $\mu \mathrm{A}$ and many tens of $\mu A$. Immediately after extraction the ions are accelerated to $20 \mathrm{keV}$ and passed through a molybdenum aperture plate to limit the divergence ball angle to $150 \mathrm{mrad}$. A $50 \mathrm{~mm}$ diameter gridjed eimel lens is lorated $105 \mathrm{~mm}$ Irom the needle. On the test bench this lens focussed the beam at a set of slits and a

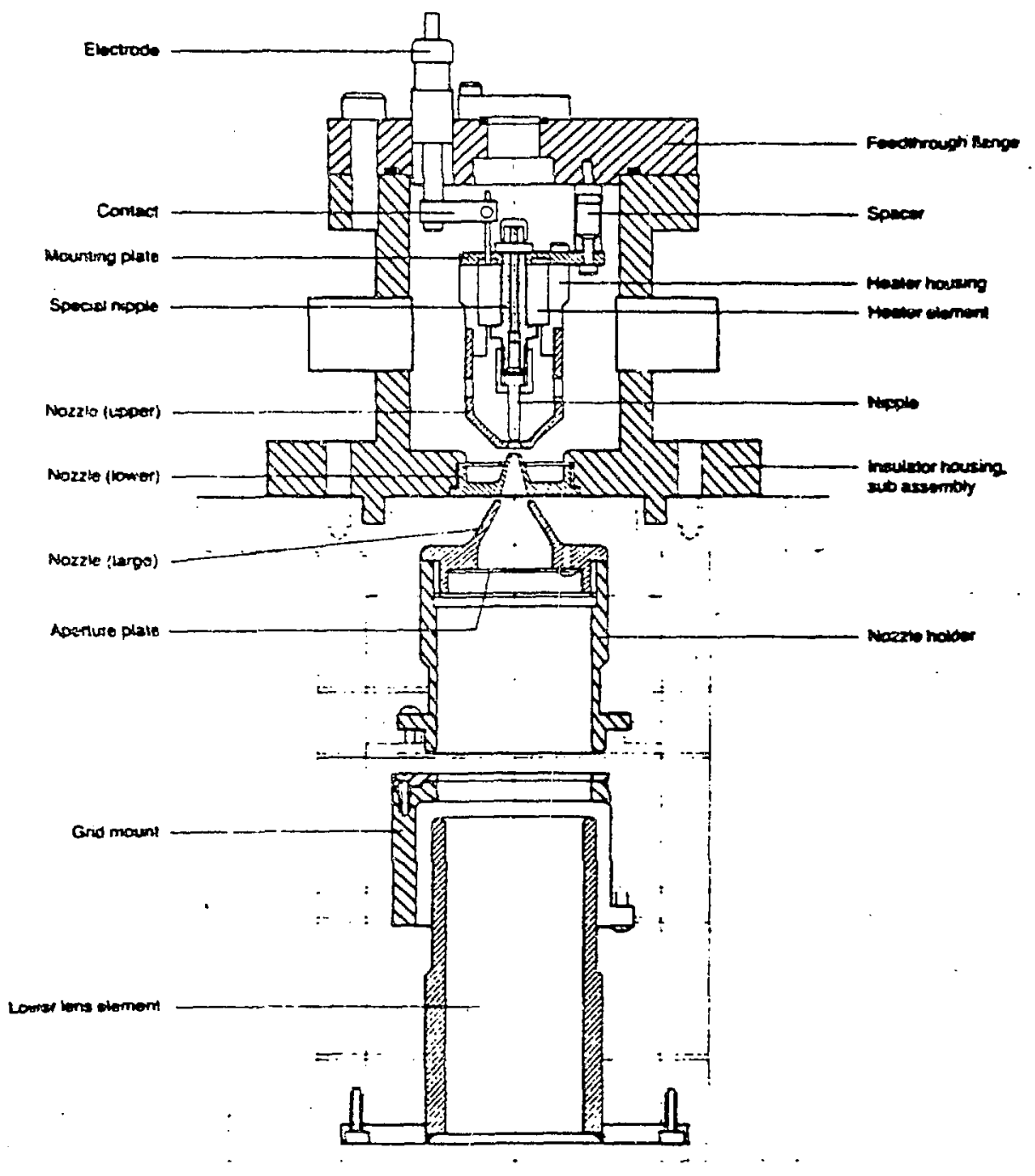

Fig. 6. A whematic of the LMIS housing and foxuswing lens. The tungsien needic, which is not shown. is locuted centrally in the nipple and protrudes by approximately I $\mathrm{mm}$. In the present studics the nippic was replacerd with a commercially available gallium source [13]. The extraction voltage is applied to the necdle and the whole source housing sub asembly is Moaled to the acceleration voliage. 
suppresicd Faruday cup $350 \mathrm{~mm}$ furhice downstrcam. With a source curren of $45 \mu \mathrm{A}$ the beam passing through a $5 \mathrm{~mm}$ squarc apcrture was $2.2 \mu \mathrm{A}$. The theoretical estimates $|14|$ of $0.1 \mu \mathrm{m}$ for the virtua! source size indicate that the beam is severely abcrated. To investigatc this the acceptance solid angle of the lens was reduced by a lacior of four. The bean current passing through the 5 min square aperture and into the Faraday cup was only marginally reduced to $2.0 \mu \mathrm{A}$ Assuming that at a source output of $45 \mu \mathrm{A}$ the angular intensity is constant up to $150 \mathrm{mrad}$ then in the absence of aberrations the curtent would be expected to drop by a factor of 4. As this is clearly not the casc it indicatcs that aberrations are a major contribution to the image sizc. A new focussing system is now being cotusidered with a view to reciucing spherical aberration whilst maintaining the beam current at the $\mu \mathrm{A}$ level. The lens should ideally be located close to the needle and have high magnification to reduce aberrations in the accelerator.

A LMIS with the present focussing lens has been installed on the Ladderton accelerator to investigate any transmission or operational problems. The source struck easily and a bearr was acce!crated to $2 \mathrm{MeV}$. Observation of the beam emerging from the accslerator indicatcd it to have a similar size to that from the if ion source. This is expected because in both cases the beam is an image of the gap lens aperture plate (see fig. 1 ). Bccause of the high magnetic rigidity of the be am analysis could only be performed using a $15^{\circ}$ magnet with a resolving power of 1 in 50 amu. The combined beam current of the two isotopes of gallium, which wer: not completely resolved, was $1.7 \mu \mathrm{A}$. Doubly charged galliurn was present at $4 \mathrm{nA}$ and contaminant beams of singly and doubly charged oxygen were present at 70 and $10 \mathrm{nA}$ respectively. The magnet did nor have surficient lield strength to analyse polyatomic gallium. The results of a secondary ion mass spectrometry (SIMS) depth profile of a test implantation of gallium into aluminium is shown in lig. 7. Impiantation was performed at $2 \mathrm{MeV}$ to a dose of $1.4 \times 10^{16}$ ions $\mathrm{cm}^{-2}$. The mean range is $1.1 \mu \mathrm{m}$.

\section{Energv spread}

The energy spread in the accelcrated beam appears at present to be limited by an oscillation in the stabiliser slit differential amplifier. This oscillation may be due tn the ion source mechanically vibrating at the altemator frequency of $25 \mathrm{~Hz}$. Whilst such beam movements do not have a dramatic effect on the beam carrent on larget they can alter the sriall amount of beam being scraped off on the pickup slits by up to $100 \%$. The stabilisation system attempts to correct these beam current changes due to vibration by changing the beam energy and therefore iniroducing an energy spread. The

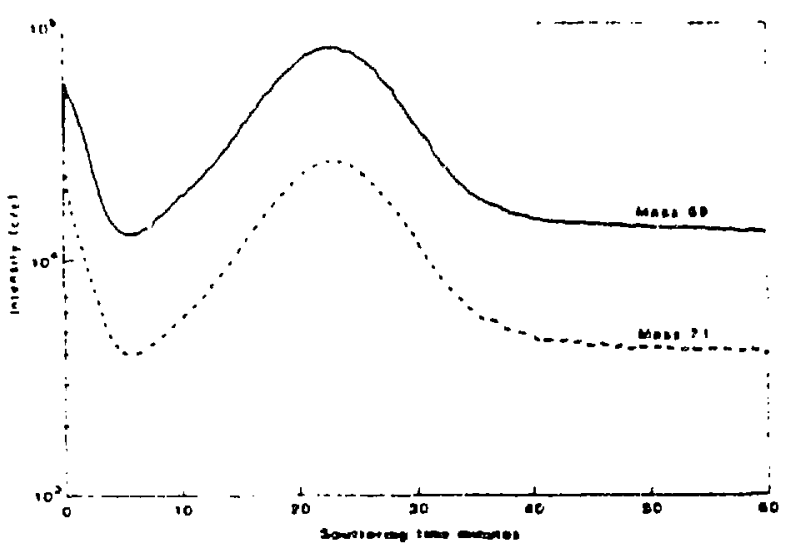

Fig. 7. A SIMS depth proñte of a I MoV gallium implantalion ins stuminium. The mean range is $1.1 \mu \mathrm{m}$.

vibration problem is to be addressed by balancing the alternator and its drive shaft and improving the mechanical decoupling of the ion source and accelerator tube from the high voltage terrinal and column.

\section{Summan}

The Hawell microprobe lens has been relocated from an oid $3 \mathrm{MV}$ Van de Graaff to a recently commissioned 5 MV Laddertron acolerator. Although the Laddertron uses an if ion source similar to the $V$ an de Graalf, a threefold increase in brightness in the microprobe line has been achieved. The improvement is due in part to the improved current stability of the Ladderuron bean. This brightness improvement, logether with a $40 \%$ reductics in the energy spread of the accelerated beam, has translated to a spot size of approximately $2 \times 2 \mu \mathrm{m}$ with a current of $150 \mathrm{pA}$ and a best resolution of $1.4 \mathrm{~km}$ in one direction. Both these results were obtained with a quadrupole doublet configuration.

Preliminary studies of the feasibility of using a LNIS to increase the brightness of a high energy microprobe have been reported. Toey indicate that while the beam can be successiully accelerated through the existing optical system the brightness is only comparabie to an if ion source. This degradation of brightness it comparison to reported values is due largely to the spherical aberration of the injector lens. The design of a low aberration lens is being investigated.

The authors are gratelul co Dr. P.D. Prewett of IBT Dubilice Limited for providing the gallium LMRS used in these studies and to AE Ledbury for carrying out test bench measuremenes. Work described in this report was undertaken as par of the Undertying Research Programme of the UKAEA. 


\section{References}

(1) JA. Cookson and F.D. Pilling. AERE Reporl R6300 (1970): J.A. Cookson. A.T.G. Ferguson and F.D. Pilling. 1. Radicanal. Chem. 12 (1972) 39.

(2) R. Levi-Setti, Nucl. Instr. and Meth. 168 (1980) 139.

[3] R. Clampitt and D.K Jelleries. Nucl. Instr. and Meth. 149 (1978) 739.

(A) R.L Seliger. J.W. Ward. V. Wang and R.L Kubena. Appl. Phys. Lett. 34(5) (1979) 310.

(5) G.L. Allan. J. Zhu and G.J.F. Legge. Fourth Aust. Conl. on Nucl. Techs. (1985) 49.

16) R Clampitu and D.K. Jefleries. LEIB Salford (1978) Insi. Pbys. Conl. Scr. (1978) no. 38.

[7] P.M. Read and J.H. Sievens. AERE Report R-11946
(1986): P.M. Read and J.H. Sievens, Nucl. Instr. and Vieth. A249 (1986) 141.

[X] F. Wall and G.W. Girme, G.D. Blower and J. Takacs. IEEE Trans. Nucl. Sci. NS28 (1981) 1413.

(9) G.J.F. Lezge. D.N. Jamieson. P.MJ. O'Brien and A.P. Mazzolini. Niscl. Instr. and Meth 197 (1982) 85; GJ.F. Legge, privale commurication (1985).

[10] T. Greenway. OPTRYK. Oxlord Nucieas Physics Laboralory Internal Report

(11] A. Vermeer and B.A. Strasters. Nucl Instr. and Meth. 157 (1978) 427 .

[i2] G.W. Grime and F. Wath Beam Opties of Quadnupole Probe-forming systerns (Adam Hilger. Bristol. UK. 2984).

(13) IBT Dubilier Lid., Abingdon. Oxon. UK.

[14] J.W. Ward, J. Vac. Sci. Technol B3 (1985) 207.

\section{DISCLAIMER}

This report was prepared as an account of work sponsored by an agency of the United States Government. Neither the United States Government nor any agency thereof, nor any of their employees, makes any warranty, express or implied, or assumes any legal liability or responsibility for the acciracy, completeness, or usefulness of any information, apparatus, product, or process disclosed, or represents that its use would not infringe privately owned rights. Reference herein to any specific commercial product, process, or servic by trade name, trademark, manufacturer, or otherwise does not necessarily constitute or imply its entorsement, recommendation, or favoring by the United States Government or any agency thereof. The views and opinions of authors expressed herein do not necessarily state or reflect those of the Urited States Government or any agency thereof. 